\title{
O pensamento higienista do intelectual Arthur Ramos na obra Saúde do Espírito (1958)
}

\author{
The hygienist of intellectual thought Arthur Ramos in work Saúde do Espírito (1958)
}

\author{
Roseane Maria de Amorim \\ Doutora em Educação \\ Professora da Universidade Federal de Alagoas \\ roseanemamorim@gmail.com
}

Lílian Bárbara Cavalcanti Cardoso

Mestre em Educação

Professora da Universidade Federal de Alagoas

lilianbarbara.cc@gmail.com

Fernanda Lays da Silva Santos

Mestranda em Educação da Universidade Federal de Alagoas nandalays.sjc@gmail.com

Resumo: Neste artigo nos propomos a analisar a obra Saúde do Espírito (1958) publicada pelo intelectual Arthur Ramos fruto de sua experiência no Serviço de Ortofrenia e Higiene Mental. O intelectual investigou a causa do comportamento de mais de 2000 crianças tidas como anormais. Assim: Quais as contribuições de Arthur Ramos à educação? Até que ponto esteve presente as propostas higienistas no projeto de educação? A nossa metodologia é baseada em pesquisas bibliográfica e documental. O pensamento de Arthur Ramos trouxe contribuições para a educação contemporânea, pois seu pensamento é atual por tratar do papel da família na formação da personalidade da criança, no entanto o foco era a prevenção de condutas tidas como indesejáveis, buscando construir a tão sonhada sociedade civilizada.

Palavras-chave: Higiene Mental, Arthur Ramos, Saúde do Espírito.
Abstract: In this article we propose to analyze the work of the Saúde do Espírito (1958) published by intellectual Arthur Ramos result of his experience in Orthophrenology Service and Mental Hygiene. Intellectual investigated the cause of the behavior of more than 2,000 children seen as abnormal. So: What are the contributions of Arthur Ramos to education? To what extent was this the hygienists proposed in the education project? Our methodology is based on bibliographical and documentary research. The thought of Arthur Ramos brought contributions to contemporary education because their thinking is present by treating the family role in the child's personality development, but the focus was on the prevention of behaviors regarded as undesirable, seeking to build the long awaited civilized society.

Key-word: Mental Hygiene, Arthur Ramos, Health Spirit. 


\section{Notas Introdutórias}

O presente artigo tem por finalidade traçar uma análise sob uma das obras do alagoano Arthur Ramos, intitulada Saúde do Espírito. O objetivo é refletir sobre o pensamento do médico acerca da Higiene Mental e desta forma associar as ações do movimento higienista à educação no início do século XX. O livro analisado se encontrava na sétima edição quando fora publicado em 1958 pelo Serviço Nacional de Educação Sanitária do Ministério da Saúde. Ao que podemos deduzir que este circulou por alguns estados do Brasil, entre eles o Rio de Janeiro, por ser de iniciativa de um órgão público federal como uma cartilha de guia para higiene mental da população.

O fato de se encontrar na sétima edição nos remete a ideia de que este fora publicado há algum tempo antes dos anos de 1950 - especificamente a primeira publicação em 1939 - e foi reeditado por servir ao interesse do governo federal o qual tange às políticas direcionadas a saúde e educação da população brasileira. O contexto de publicação deste livro está envolto aos anseios de ordem e progresso ${ }^{1}$ para a racionalidade científica e na industrialização estes fatos fermentaram os pensamentos dos intelectuais que enxergavam a educação como um instrumento importante para a realização da modernização em alguns lugares do país.

O movimento higienista tornou-se notório ainda no século XIX, pois seus adeptos seguiam o que tinha de mais inovador na área das ciências biológicas, humanas e sociais neste período. Entre algumas teorias consideradas científicas podemos destacar as variações do evolucionismo de Charles Darwin (1809-1882) que fundamentam as teorias raciais, sendo elas a Eugenia de Francis Galton (1822-1911) e o darwinismo social de Herbert Spencer (1820-1903). O primeiro fundamentou os estudos estatísticos sobre a inteligência humana através de testes de QIs, em que evidenciava a classificação dos indivíduos inferiores e superiores. Para o autor dessa teoria, a inteligência era hereditária e por isso foi disseminada a seleção dos mais úteis para sociedade capitalista. Nesse sentido foi estabelecido que as raças inferiores (negro e índio) deveriam ser eliminadas por meio de cruzamento desejáveis e em detrimento o nascimento de sujeitos superiores (branco europeu) para compor a nação, contribuindo para sua evolução. A segunda perspectiva teórica influenciou bastante os ordenamentos curriculares no final do século

\footnotetext{
${ }^{1}$ A ordem e progresso estavam inseridos na corrente filosófica positivista. O positivismo defendia que deveria estabelecer uma ordem para alcançar o progresso, e através da ciência seria possível formar uma elite dirigente que organizaria a sociedade.
} 
XIX, e assim por diante, na concepção de Herbert Spencer, era por meio de uma educação física e moral que uma nação obteria a ordem, e assim, o tão sonhado progresso. Houve outras teorias como a psicanálise, conforme Ramos (1958), que ajudou no tratamento dos ditos alienados, que eram considerados pessoas que apresentavam desvio de comportamento como, por exemplo: vícios, psicoses, neuroses, ociosidade, ou simplesmente, por ser diferentes na forma de agir ou ser tendo como referência uma norma, um padrão.

Quanto ao perfil e ações/ intervenções dos higienistas, encontravam-se: engenheiros que se empenharam em fazer reformas sanitárias nos centros urbanos para evitar a proliferação de doenças e facilitar a circulação típica do movimento do crescimento da indústria e do comércio que aqui se iniciava; tivemos os advogados e juristas das faculdades de Direito que por meio da lei e de suas revistas propagavam discursos sobre raças e moralidade da população; entre os higienistas também se destacaram os médicos que por meio de instituição de pesquisa e clínicas de higiene mental buscavam por meio de intervenções prevenir e corrigir as doenças sociais, como alcoolismo, a proliferação de doenças como sífilis, as doenças mentais (alienados), o desvio de caráter que induz aos vícios como a jogatina, a violência e os roubos, entre outros. Assim, como promoviam campanhas educacionais, intervinham por meio de vacinas e promoviam o saneamento urbano junto aos engenheiros reformistas.

O grupo de higienistas que nos interessa é o dos médicos, pois este trabalho será desenvolvido sob a ótica do intelectual e psiquiatra Arthur Ramos. Desse modo, o escolhemos por dois motivos: o primeiro está associado à importância dos estudos históricos que resgatam a memória local por meio do levantamento dos intelectuais alagoanos com a intenção de contribuir para a sua formação identitária e segundo porque as pesquisas e os trabalhos deste médico na área da higiene mental e na antropologia foram numerosas e valorosas para o Brasil, sendo considerado por muitos historiadores biográficos, como um homem além do seu tempo.

Arthur Ramos (1903 a 1949), médico psiquiátrico, se destacou desde a infância nos estudos e atuação na cidade de Pilar como escritor do jornal local, orador, dentre outros. Em 1926, ingressou na faculdade de medicina na Bahia o qual desenvolveu várias pesquisas relacionadas à medicina legal, psiquiatria, educação, antropologia, sociologia, etnografia, cerca de 458 estudos. Ramos destacou-se com seus estudos sobre psicanálise, trocando correspondências com o próprio fundador da Psicanálise, Sigmund Freud, sendo reconhecido por este. Após publicar várias pesquisas sobre educação e psicanálise e de 
ser adepto ao movimento higienista, que veio a se propagar no Brasil no início do século XX. Ramos foi convidado por Anísio Teixeira para chefiar o Serviço de Ortofrenia e Higiene Mental, no Distrito Federal, que atuou no período de 1934 a 1939, resultando nas obras Criança Problema (1939) e Saúde do Espírito (1958).

O objeto de análise deste artigo tem como fonte o livro Saúde do Espírito, e para tanto, com base em Marc Bloch (2001), buscamos entender que a vida humana é rica em múltiplos aspectos e as fontes históricas por si só não falam, são as perguntas elaboradas pelos pesquisadores/as que dão vida aos documentos sejam orais ou escritos. Corroborando com essa mesma ideia, Arlette Farge (2009) afirma que os documentos impressionam pela posição ambígua em que se apresentam; é preciso desvendar dramas cujos homens e mulheres não estão pintados por inteiro, são breves vestígios de fragmentos que contam partes do que aconteceu. Por isso escolhemos como estratégia de pesquisa a análise documental e bibliográfica que teve como parâmetro os estudos de Cynthia Veiga (2007), José Gondra (2005), Diana Vidal (2008), entre outros.

Esta metodologia busca responder as seguintes problemáticas: o que diz no livro Saúde do Espírito (1958)? A quem se destinava a proposta higiênica de Arthur Ramos? Tendo como concepção que o homem está imerso em seu tempo, qual a finalidade da proposta pedagógica do psiquiatra alagoano para a formação do indivíduo e da sociedade? Há relações de poder presente na proposta higienista apresentada na obra? Além disso, como se destaca as limitações e contribuições do pensamento do intelectual para a educação na referida obra? Como estão presentes as propostas de Ramos na atualidade? Desse modo, temos como intuito analisar o pensamento do alagoano Arthur Ramos; identificar as limitações e contribuições da proposta do intelectual para à educação; problematizar o tratamento dado à infância e suas implicações para a formação humana e da sociedade.

Para tal propósito, o nosso trabalho apresenta ao leitor quem foi Arthur Ramos e sua trajetória profissional, a princípio, que em linhas gerais, foi um médico alagoano, de notável atuação no campo da medicina, antropologia, educação, dentre outros, desse modo, indo além de seu campo de atuação, intervindo no meio social, buscando se legitimar socialmente através do saber médico. Cabe uma questão: por que o saber médico se mostra como um saber privilegiado, intervindo na educação?

Veremos a seguir, com mais detalhes, o quanto esse saber esteve imerso em um projeto de sociedade moderna. Ao fim desta discussão primeira, iremos nos deter à análise da obra Saúde do Espírito (1958) que foi fruto da atuação de Arthur Ramos no Serviço 
de Ortofrenia e Higiene Mental (1934 a 1939) o qual analisou o comportamento de mais de 2000 crianças de escolas públicas do Rio de Janeiro, na gestão educacional do escolanovista Anísio Teixeira. Contudo, o intelectual em foco, em resposta a análise das crianças problemas estudava o comportamento tido como anormal de crianças com comportamentos “desajustados", ou seja, um manual destinado à população e professores a lidar com estes, de forma eficaz, mostrando-se como a "salvação" para os problemas que impediam a ordem e o progresso da sociedade moderna.

\section{O intelectual alagoano Arthur Ramos}

Arthur Ramos de Araújo Pereira, filho do médico Dr. Manuel de Araújo Pereira e dona Ana Ramos de Araújo Pereira, foi uma das figuras mais ilustres de Alagoas, em paralelo ao nosso querido Graciliano Ramos. Oriundo da cidade de Pilar, em Alagoas, nasceu no dia 7 de julho de 1903. A lagoa Manguaba ${ }^{2}$, testemunha da infância do intelectual, banha a cidade de Pilar considerada na época "um grande porto lacustre, por onde se escoava o açúcar de todos os engenhos das vizinhanças, além da produção das fazendas e o carvão, em demanda de Maceió". (BARROS, 2005:20)

Descendente do Capitão Domingos Ramos de Araújo, seu avô, que escolhera a cidade como seu lócus vivencial, após a morte de sua esposa Jacinta Henriqueta de Araújo Pereira, em Quebrangulo ${ }^{3}$. Este fato ocorreu nos meados dos anos de 1820. Segundo Luitgarde Barros (2005) a vinda das famílias de Quebrangulo:

O médico pesquisador Dr. Pedro Costa Pereira encontrou o registro da chegada do capitão Domingos, vários casais e familiares em Quebrangulo em 1820, fugidos das perseguições aos sediciosos da revolução de 1817 em Pernambuco. É sua informação de que, diferentemente do irmão Francisco de Araújo Pereira, o capitão Domingos, por ter nascido no dia de Ramos, incorporou Ramos ao próprio sobrenome, transmitindo-o a seus descendentes (BARROS, 2005, p.20).

A família de Ramos era bem instruída, possuía um gosto pela preservação da

\footnotetext{
${ }^{2}$ A lagoa Manguaba é a maior do Estado de Alagoas com 34 quilômetros quadrados. Esta lagoa está localizada no litoral médio do estado de Alagoas.

${ }^{3}$ Quebrangulo é um município do Estado de Alagoas. Situa-se na parte norte, faz parte da Microrregião de Palmeira dos Índios, antigamente denominada de "Zona da Mata".
} 
memória social, isto está explícito no fato de serem depositárias de documentos do passado, seus e da vida sociocultural do mundo em que viveu. A vida desse intelectual trás em sua bagagem costumes alagoanos de famílias ilustres que viveram as últimas décadas do século XIX.

Guardando partituras musicais, panfletos de greve, programas teatrais e panfletos denunciando escândalos políticos, a família Ramos preservou, não apenas através de vasta correspondência, fragmentos da história da cultura e da vida coletiva em Alagoas (BARROS, 2005:22).

Seu pai incentivava a leitura e a família possuía uma biblioteca rica, onde amigos de Ramos, de seu pai e dos irmãos iam desfrutar no Pilar da grande biblioteca de sua casa. O convívio familiar deste intelectual foi determinante para a sua formação e nos leva a refletir sobre o papel da família no processo de aprendizagem.

Formado em 1926 pela Faculdade de Medicina da Universidade da Bahia, leciona clínica psiquiátrica. Considerado um homem além do seu tempo, além da medicina legal, ampliou suas concepções teórico-científicas fazendo incursões em áreas como a psicologia, a psicanálise e mais tarde na antropologia. "Como estudante no Pilar, Maceió, e depois em Salvador, Arthur Ramos se entrega à frenética busca de ampliação de seu mundo, devorando livros, participando de grupos literários e de edições de jornais" (BARROS, 2005:22). Chegando a trocar cartas com Freud, um dos teóricos que o influenciou fornecendo subsídios na área da psicanálise.

Ao longo de sua vida Ramos exerceu vários cargos públicos entre eles, o de Catedrático de Antropologia e Etnologia da Universidade do Brasil, Chefe do Departamento de Ciências Sociais da UNESCO, Professor de Psicologia Social da Universidade do Distrito Federal, Chefe do Serviço de Higiene Mental do Departamento de Educação do Rio de Janeiro (GARCIA, 2008:06).

Médico psiquiatra, psicólogo social, etnólogo, folclorista e antropólogo brasileiro, foi um dos principais intelectuais de sua época, buscou contrapor as teorias raciais que evidenciava a inferioridade das etnias negra e indígena propondo uma teoria cultural, e folclórica, e por isso destacou-se na construção do mito da democracia racial. Outro importante feito foram seus estudos que ajudaram no processo de institucionalização das Ciências Sociais, assim como, o primeiro a introduzir a 
experiência do uso da psicanálise e a antropologia na educação do Brasil.

Muda-se para o Rio de Janeiro no início da década de 30, em 1934, assume a chefia da seção de Ortofrenia e Higiene Mental do Instituto de Pesquisas Educacionais, órgão ligado ao Ministério da Educação e Saúde. Neste período “viveu a euforia idealista e esperançosa do movimento de 30" (BARROS, 2005:28), através de sua participação na Reforma de Anísio Teixeira no Rio de Janeiro, a qual visava a implantação de um sistema de ensino completo, desde a pré-escola até o ensino superior com a criação da Universidade do Distrito Federal. A intenção era aplicar na prática o ideário do Movimento Escola Nova, com reformulação didático-pedagógica e de estrutura.

É mister afirmar que foi neste período que elaborou suas principais contribuições para educação, como o caso do livro "A criança problema" e "Saúde do Espírito, ambas de 1939, o segundo reeditado em 1958”. Em meio a sua história social e pessoal vamos ao traçado de seu pensamento em uma de suas principais obras, Saúde do Espírito. No entanto, para fins elucidativos, já podemos destacar, a priori, que o livro em foco se apresenta como um manual, defendendo uma formação de hábitos, em especial, para os adultos lidar com a criança em busca de pessoas ajustadas a sociedade moderna. Assim, na obra foi tratada questões como relação criança e adulto em seus círculos sociais, sobretudo a família e escola que se não seguir os preceitos do higienismo pode trazer sérios "prejuízos” à criança, família e sociedade. Neste sentido, o pensamento de Arthur Ramos, envolve questões muito pertinentes para o campo educacional como concepção de infância, tratamento dado a criança (excessos de mimos ou mal tratos), sexualidade e gênero, formação do professor, dentre outros, que ao analisar mais detalhadamente, iremos relacionar com as questões atuais, fortemente marcadas em nossa sociedade.

\section{Saúde do Espírito (1958): Higiene mental e educação}

$\mathrm{Na}$ imagem do livro em estudo, na própria capa tem "Serviço de Educação Sanitária", o que podemos observar que a proposta higienista de "limpar mentes" dos vícios que levariam ao comportamento desajustado tinha vínculo com a educação da sociedade, havendo apoio dos governantes para isso, vejamos a imagem que segue abaixo: 
Imagem 1: Capa e contra-capa do livro Saúde do Espírito (1958).

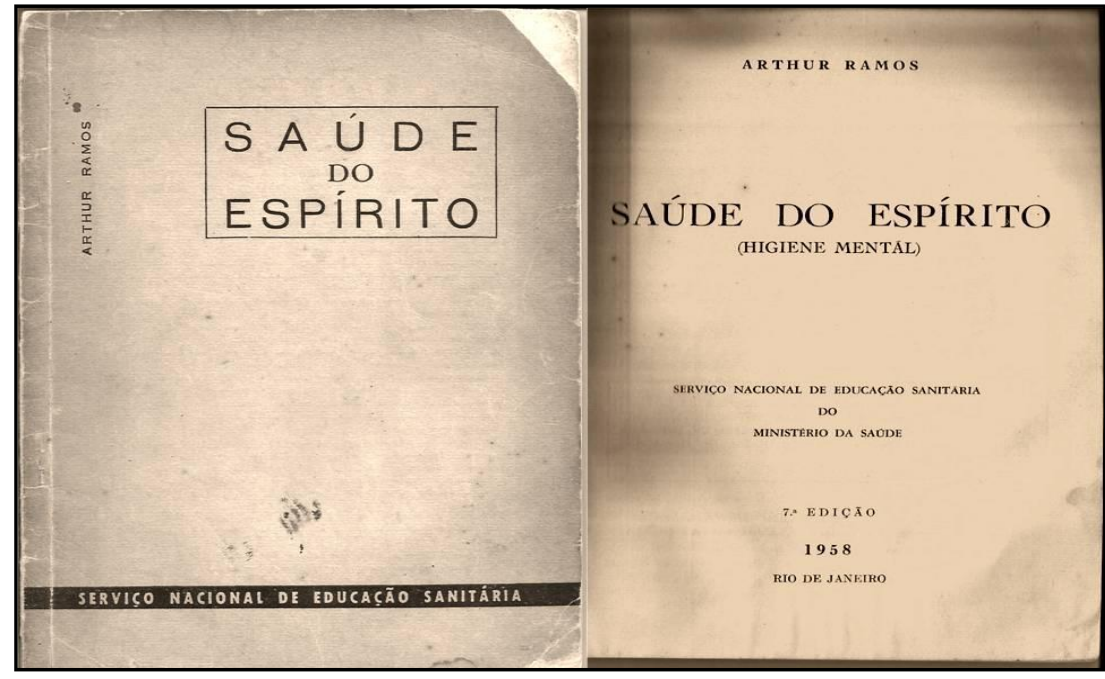

Fonte: Acervo particular.

O saber médico veio a ocupar um saber privilegiado no contexto social no início do século XX, no Brasil, perpassando de seu campo de atuação, intervindo no campo educacional e social. Nesse sentido, os médicos ao justificar que as alterações no comportamento foram originadas no cérebro, isto é, questão orgânica, objeto de estudo da medicina, assim, ficou delegada à psiquiatria intervir no tecido social, nos problemas sociais, conforme Caponi (2012). Mas o que o livro Saúde do Espírito: Higiene Mental vem a nos dizer sobre a intervenção médica no campo pedagógico? A que ponto o pensamento do psiquiatra Arthur Ramos se aproxima e se separa das propostas higienistas e eugênicas? Quais as limitações e contribuições do intelectual para entender a educação no campo da história da educação e para problemáticas atuais? Não temos a pretensão de discutirmos essas questões de maneira aprofundada, mas trazer algumas reflexões que nos auxiliem a pensar o campo educacional.

Arthur Ramos publicou o livro Saúde do Espírito em 1939, reeditado em 1958, nele há a defesa do estudo das causas do comportamento, o qual ele vai além da genética considerando o meio social como fator preponderante para o comportamento humano, isso fica claro nas primeiras páginas da obra supracitada. Desse modo, o pensamento do intelectual se afasta da concepção do puramente genético, no entanto, é influenciado pelo higienismo, não mais de cor, mas de cultura, embora que a população negra fazia parte dessa cultura da classe popular a ser; logo, higienizada. $\mathrm{O}$ autor veio a investigar crianças rotuladas como "anormais" trazendo contribuições para investigar as causas do comportamento, contribuindo para se pensar na não medicalização do comportamento, 
questão essa muito atual.

A época que a obra foi elaborada e publicada estava permeada por transformações sociais importadas da Europa com conceitos sobre infância, pedagogia nova, economia capitalista, além de todo o contexto da herança escravocrata. Com a abolição da escravatura (1888) e aumento da classe popular com o advento da urbanização, a elite econômica/social não mediu esforços para a construção de um "novo" projeto de nação. Para alcançar tal intento Educação e Medicina se tornaram instrumentos de poder para a formação da nação moderna, ocupando um dos lugares centrais nas políticas educacionais e de governo.

A ciência positivista aplicada à escola adentrou por meio dos discursos educacionais e médicos que circularam no início do século XX tanto por meio de políticas, reformas, formação de professores como publicação e divulgação de livros sobre a temática. Em obras de cunho higienista e eugenista, o intuito era justificar a "inferioridade" reportando-se ao evolucionismo, darwinismo social como havendo a evolução das raças, sendo a brancura a "perfeição", e a miscigenação a "degradação", sendo um tipo de retrocesso, e logo, inferior, trazendo argumentos biológicos e científicos para justificar o preconceito por meio dessa ideologia. Ramos vai além dos argumentos biológicos, mas a ciência é argumento principal de sua proposta de formação de hábitos. Hábitos esses, de conduta, de pensar, de ser, de agir. Haviam relações de poder?

[...] Reformar a escola, reformar a indústria, o hospital, o exército, a prisão; mas todos sabem que essas instituições estão condenadas, num prazo mais ou menos longo. Trata se apenas de gerir sua agonia e ocupar as pessoas, até a instalação de novas forças que se anunciam. São as sociedades de controle que estão substituindo as sociedades disciplinares [...] (DELEUZE, 1992: 220).

Observa-se que podem ser mudados os mecanismos de dominação e controle, mas que sempre há relações de poder, "liberdades e sujeições" nas relações sociais e no regime em vigor. No entanto, não podemos cair na armadilha do determinismo, pois com a revelação das ideologias e o protagonismo dos atores sociais, pode haver sim uma mudança social e efetivação de direitos, pois todos são detentores de poder no lugar em que se encontram (CORAZZA, 2001).

Mesmo trazendo contribuições, sendo contrário ao ensino tradicional, ou seja, castigos físicos causadores de traumas e neuroses, Ramos (1939) é a favor do ideário 
escolanovista, busca a formação de hábitos, tendo em vista determinada cultura, saber e poder. Nesse sentido, o intelectual está engajado em um regime social e político que não é o de transformação social. Se não fosse assim, por que seria necessária a formação de hábitos de condutas, morais, normalizações para a população? Hábitos para quê?

Nesse momento havia um crescente movimento fascista e nazista no mundo, que pretendia aplicar o conceito de raça pura (ariana) a políticas de governo, pois haviam partidos nazistas criados no Sul do Brasil com o advento da imigração. A higienização da mente tem haver com medicalização, branqueamento, ou seja, a Eugenia ${ }^{4}$. Sendo esta destacada por Gondra (2005) como a vontade de intelectuais da época, a exemplo, Afrânio Peixoto, de produzir um homem novo, assim formando "um tipo humano mais perfeito que o existente".

O pensamento de Arthur Ramos se aproximava da eugenia, no que diz respeito ao constructo de uma sociedade limpa, ordenada e adaptada à sociedade capitalista, e isso é o cerne da modernidade. Com a higienização da mente aplicada à escola contida no livro Saúde do Espírito: Higiene Mental (1939, reedição 1958) o intelectual orienta a formação de hábitos “saudáveis” para o espírito, comportamento. Que hábitos seriam esses? E a quem se destinava?

Assim: "[...] o aumento do número dos tipos normais e a diminuição e o desaparecimento final dos subnormais [...]”. (DOMINGUES, 1994:43). Sendo, a eugenia um desdobramento do projeto de higienização. De algum modo Arthur Ramos colaborou para esses processos profundamente racistas, mas que eram entendidos como necessário para tornar a sociedade brasileira civilizada, semelhante ao europeu. Assim vários cientistas estavam engajados nesta luta, desde o médico, o psiquiatra, o psicólogo, o pedagogo e o antropólogo. De algum modo o intelectual alagoano era uma síntese desse propósito. Nesse momento, as propostas higienistas e eugênicas ganham maior espaço no cenário brasileiro, com o intuito de prevenir o comportamento indesejável, tendo como foco de atuação a família dos ditos anormais.

Com o intuito de constatar tais questões mencionadas acima, voltemos ao livro Saúde do Espírito que foi fruto da atuação do psiquiatra alagoano durante cinco anos no Serviço de Ortofrenia Higiene Mental - SOHM -, na gestão educacional de Anísio Teixeira, como já mencionado. Arthur Ramos aborda sobre seu trabalho em escolas

\footnotetext{
${ }^{4}$ Francis Galton, cientista evolucionista britânico e primo de Charles Darwin, criou o termo Eugenia derivada da junção de dois vocábulos gregos: eu (bem)+ genos (raça, linhagem, espécie), a que significa então bem-nascido ou boa espécie.
} 
experimentais analisando mais de 2000 crianças ao todo, desse modo, buscava identificar às possíveis causas psicossociais de comportamentos "desajustados" de escolares com problemas. Tinha o intuito de investigar os círculos de vida da criança através de métodos científicos, a fim de constatar a origem do comportamento das crianças "indisciplinadas" e com dificuldades de aprendizagem, indo além de testes simplistas e rotuladores como ele destaca. O propósito era conhecer as raízes dos comportamentos tidos como indesejáveis para formar uma sociedade ideal, buscando o ajustamento aos novos padrões conduzidos pelo liberalismo burguês, a indústria e a Ciência. Assim nos afirma que:

Foi organizada a Ficha do Serviço, onde se colhem os dados da família (pais, irmãos, outros parentes...), ambiente familiar (condições materiais e psicológicas da habitação...), história obstétrica materna, desenvolvimento e formação de hábitos (crescimento, saúde geral, alimentação, marcha e linguagem, ritmos fisiológicos, disciplina e vida na escola), fachada temperamental e caracterológica, funções psicológicas, súmula do exame psicométrico e antropométrico, fornecidos pelos Serviços correspondentes, exame médico, diagnóstico da personalidade [...] (RAMOS, 1958:28).

O intelectual em questão via nos princípios da Psicanálise a oportunidade de introduzir a higiene mental na escola com intuito de através dela prevenir e/ou corrigir a conduta humana rumo à formação de indivíduos considerados sadios. Observa-se que o saber médico seria um instrumento de regulação social, pois o castigo físico seria substituído por um controle internalizado pelo próprio indivíduo através dos hábitos, sendo mais eficaz, conforme Vidal (2008), pois estaria naturalizado. Assim, seria interessante para evitar que: “[...] Muitas vezes, os conflitos calados da infância vão explodir mais tarde, na vida adulta, ao mais pequenino pretexto" (RAMOS, 1958:54). Logo, haveria o controle social, evitando a desordem e rebeliões. É interessante destacar que os psiquiatras higienistas e eugenistas da época tinham a visão de prevenir, e não de curar, por isso a idade de "ouro" para atuação da higiene mental seria desde a mais tenra idade, ou seja, o foco maior seria a criança.

A obra Saúde do Espírito (1958) tornou-se um instrumento para divulgar as constatações e descobertas de Ramos em sua atuação no SOHM, que por sua vez, envolve uma intencionalidade, para a população de um modo geral. A enunciada é dividida em dez capítulos em que são retratados sobre a história da psiquiatria (brevemente), herança e meio, infância, sexualidade, família, professor e escola. 
A higiene mental é centro da discussão da obra mencionada acima onde Arthur Ramos apresenta regras dirigidas a pais e educadores de como conduzir a criança. Desse modo: "Procura dar regras práticas e gerais para a correção dos desajustamentos e conflitos psíquicos, que geram a angústia, a incapacidade e a dor” (RAMOS, 1958:7), e para evitar esses desajustamentos psicossociais, o psiquiatra defende a importância de aplicar as ideias da higiene mental na infância através da educação, a fim de evitar o "adoecimento" dos adultos.

Seguindo esse viés, Ramos busca convencer a população sobre a importância da higiene mental sobre a qual defende seus princípios atrelados à educação familiar que envolve a formação de hábitos por meio de condicionamento social e cultural. E essa proposta da higiene mental do alagoano envolve considerar os instintos tais como a fome, a sexualidade, o sono, o repouso, o jogo, como elementos intrínsecos do individuo, estes deveriam ser vigiados e controlados por meio da educação higienista: "A criança é uma entidade dinâmica vivendo a vida intensa dos seus instintos [...]” (RAMOS, 1939:36). Assim, o autor orienta o adulto a controlar esses instintos na infância.

Nessa perspectiva, via-se no médico alagoano a preocupação em orientar os pais sobre a importância do jogo/brincadeiras como atividade essencial para o desenvolvimento infantil, desde que regrado, “[...] a higiene mental, importa saber que o jogo é uma atividade indispensável à saúde física e mental da criança. Os adultos devem deixar o mais possível em "liberdade" à criança nas suas atividades de recreação". (p.41). Mas o que seria essa "liberdade"? Liberdade controlada sobre critérios psicológicos. Além disso, destaca a relevância dessa atividade para os maiores, tendo como foco central a educação dos pequenos, mas também se preocupa com a educação dos adultos, até porque um adulto sadio de espírito foi fruto de uma criança "sadia de comportamento". Assim como nos afirma que:

[...] reconhecia o valor dos jogos e da diversão também para os adultos, uma vez que atuava como uma válvula de escape na liberação de "energias instintivas". As brincadeiras e os esportes eram meios eficazes de condução dos instintos de agressividade e de libido. Afirmava o médico que assim realizava-se uma espécie de catarse (GARCIA, 2010:8).

Desse modo, à medida que os referidos instintos não fossem supridos ou exageradamente supridos, a exemplo da criança mimada e a escorraçada, isso implicaria 
no desenvolvimento de pessoas neuróticas, criminosas, psicóticas, problemáticas, isto é, desajustadas socialmente. Nessa perspectiva:

[...] o médico alagoano revelava sua mais profunda convicção no poder da ciência e na sua capacidade de superar os dramas humanos e conduzir a nação a um período de paz e prosperidade. Tudo isso em contraste com as terríveis condições de vida do país em especial da capital federal nas primeiras décadas do século XX, em meio à guerra, epidemias e a ditadura getulista (GARCIA, 2010:148).

Observa-se que Ramos estava empenhado em assegurar o progresso da nação através do controle da conduta humana, mesmo em meio a um contexto social e político desfavorável. Em outras palavras, a educação higienista seria a salvadora da nação, desconsiderando o contexto social o qual os indivíduos estavam envolvidos.

Arthur Ramos traz orientações para os pais nos capítulos sete e oito, intitulados respectivamente como As Constelações Familiares e Os dois Pólos da Criança Mimada e da Criança Escorraçada destacando a importância de "educar" as necessidades mais básicas do bebê e da criança até desvendar as artimanhas inconscientes da criança mimada. Nesse sentido, adverte aos pais sobre o controle dos castigos e da relação com e entre os filhos, a fim de evitar crianças problemáticas na escola e adultos neuróticos na sociedade. Assim destaca: “[...] o escolar problema é a resultante de vários fatores desajustados de seu ambiente familiar e escolar é com a análise e o esclarecimento destes fatores que reajustamos a situação". (RAMOS, 1958: 388)

Nesse sentido, Ramos enfatiza a importância dos pais lidarem com os filhos, sobretudo a mãe, pois esta "[...] é um grande condensador de energias psíquicas. É um “écram”, para onde a criança polariza o seu dinamismo instintivo e afetivo [...]”. (p.51). Assim, o autor advoga a relevância da mãe para a formação psíquica do filho, tendo em vista que uma mãe desorientada trará consequências desastrosas para o filho. O intelectual adverte aos pais a sua função:

Os pais devem, o mais precocemente possível, deixar a criança sozinha [...]. Acostumar a criança a ter o seu leito e o seu quarto, dormir e acordar na hora certa, adotar atitudes corretas no sono, ter o quarto e o leito em condições físicas as mais perfeitas possíveis (RAMOS, 1958:41). 
Assevera que para formar pessoas adaptadas faz-se imprescindível a postura adequada dos pais frente às necessidades dos filhos. Em suas palavras aponta:

A atitude dos pais é fundamental nesse ponto. Não é com ameaças, promessas de recompensa, ou carinho exagerado que se devem formar os hábitos da criança, com relação às suas atitudes positivas frente às necessidades da criança, apresentando-lhe os alimentos de forma variada, a horas certas, em ambientes tranquilos, condicionando a sensações agradáveis o instinto infantil (RAMOS, 1958:38).

Nesta citação, observa-se que Ramos mostra a importância de lidar com os filhos com temperança para não desenvolver a construção de uma criança mimada ou medrosa que sofrerá na fase adulta por haver a frustração tardia dos seus "caprichos", tornando-se um adulto infantilizado e dependente, sobretudo, da mãe, incapaz de lidar com os desafios de uma sociedade competitiva, industrial e moderna. É exatamente aqui onde reside o fato de que a higiene mental busca adequar a criança a um modelo de sociedade norteamericana. Nesse sentido, John Dewey (2011) também destaca o princípio de continuidade através da experiência, que influencia na formação de hábito defendida por Ramos:

[...] cada experiência afeta para melhor ou para pior as atitudes que contribuem para a qualidade das experiências subsequentes, estabelecendo certas preferências e aversões, tornando mais fácil ou difícil agir nessa ou naquela direção. Além disso, toda a experiência exerce, em algum grau, influência sobre as condições objetivas sob as quais novas experiências ocorrem [...] (DEWEY, 2011:37).

Vale destacar o outro pólo da criança, a escorraçada, tornando-a, assim, pela falta de orientação dos pais sobre os princípios da higiene mental. Segundo Ramos (1939) a criança "escorraçada", ou seja, aquela que é castigada exageradamente, desprovida do afeto familiar, maltratada, cujas necessidades e interesses são reprimidos, segundo Ramos (1939). Indo por esse raciocínio, pode tornar-se agressiva, reproduzindo tais comportamentos em outros ambientes, podendo tornar-se delinquente futuramente ou internalizar inconscientemente os traumas, desencadeando em neuroses, psicoses, sofrimento psíquico. 
Desse modo, a criança que fosse moldada a ser uma ou outra dos mencionados, traria consequências para si e para a sociedade. É interessante lembrar o conceito de governamentalidade, de Michel Foucault (1992) que aborda a questão de governar almas e condutas, que por sua vez, envolve o governo das classes dirigentes quanto o autogoverno que é internalizado pelo indivíduo, governando a si mesmo e ao outro, sendo os processos de subjetivação imprescindíveis para a lógica mercantilista, liberal. Seria uma espécie de violência, não mais física, mas sobretudo, simbólica, sútil.

Nesse sentido, vale enfatizar a educação tradicional e nova como sendo colaboradoras de indivíduos "sãos" ou "doentes". A primeira impede a criança de expressar sua criatividade, comunicação, necessidades e anseios, gerando sofrimento psíquico, enquanto, a segunda possibilita compreender a criança em seus estágios de desenvolvimento, segundo Ramos (1939). No entanto, percebe-se que ambas buscam atender a um tipo de civilização, a primeira de modo externo com punições e castigos, a segunda, conhecendo o entorno da criança que implantaria uma internalização de comportamentos que a controlaria mesmo longe da presença do adulto.

Neste momento buscamos discutir a relevância da escola na proposta pedagógica de Arthur Ramos. Para tanto, analisamos o capítulo IX intitulado A Higiene Mental na Escola no qual ele destaca o importante papel da ação conjunta da instituição escolar com a família para evitar ou corrigir a formação de uma criança mimada ou escorraçada, que, por sua vez, educadores e pais devem dialogar e agir na condução da criança.

Nesse sentido, Arthur Ramos aponta que a educação familiar repercute na escola na medida em que as crianças mimadas ou escorraçadas reagem de forma negativa, no que tange à disciplina e aprendizagem escolar; relação professor e alunos. Assim, uma criança mimada ou escorraçada seria um problema para se adaptar ao poder da sociedade no futuro, porque ela exige pessoas "disciplinadas". Podemos observar o quanto essa proposta de Ramos envolvia regulações e controle social, em que a disciplina e a civilização de corpos e almas seriam o foco maior, sendo uma estratégia biopolítica, conforme Foucault (1992). A estratégia biopolítica seria uma forma de intervir sobre o corpo com interesses políticos, sendo manipulado, não sendo do indivíduo, um corpo sem direitos, um corpo ampliado (social), conforme Sandra Caponi (2012).

Muitos conflitos, que então se formaram de maneira lenta e silenciosa no ambiente familiar, vão surgindo na Escola. E isso tanto para o caso da criança mimada, que quer continuar na Escola os seus privilégios, como para a criança 
odiada e escorraçada, que vai aproveitar do seu primeiro momento de liberdade (RAMOS, 1939:64).

Nesse sentido, o médico alagoano enfatizou que essas crianças em questão (problema) não são atendidas em seus caprichos ou estão angustiadas, por isso, tornamse agressivas, violentas ou tem um complexo de inferioridade, e ao se deparar em situações competitivas ou frustrantes não sabem lidar sem o auxílio dos pais.

Além disso, enfatiza os sintomas ou maus hábitos da criança na escola originados da "má educação" dos pais, que, por sua vez, necessita que o educador os identifique e compreenda como aspectos do meio social e passível de mudança para a possível correção dos referidos comportamentos:

[...] Aí estão os casos de preguiça e desatenção, de gagueira, de problemas de comportamento sexual, de tiques, de muitos outros problemas chamados "maus hábitos", mentiras, furtos e outras falhas que podemos filiar a "prédelinquência" infantil, de causas afetivas e ambientais, porque o seu desconhecimento ou a atitude errônea da parte do adulto podem trazer consequências perigosas, mais adiante, que parecem mínimos na infância, podem constituir o núcleo de graves distúrbios da vida adulta (RAMOS, 1939:69, sic).

O autor adverte aos adultos a necessidade de olhar para os problemas infantis, pois o que possa parecer mínimo ou temporário, ou até mesmo com um simples castigo ou expulsão possa ser solucionado (educação tradicional) é ilusão, pois a quietude devido a uma repressão, não significa a ausência de recalques profundo ou a não existência deles, mas que consequências negativas porventura surgirão no futuro. Observa-se que os adultos, nessa visão de Ramos, são despreparados, e possíveis culpados pelo comportamento das crianças.

Investigar o contexto sociocultural, isso significa o meio que a criança está inserida, sua realidade, e intervir nessa, exige um maior esforço, e o objetivo não era esse. Buscava-se agora mais que um povo instruído, e sim educado, adaptado à sociedade, conforme Vidal (2008), isto é, com "bons hábitos", e nada melhor que a escola e professores, para desde a mais tenra idade, formar esses cidadãos desejáveis ao progresso da nação.

Assim, o professor assume a tarefa de educador não apenas das crianças, mas 
também dos pais e de si mesmo. Nesse sentido, vale destacar que um adulto educado evitaria projeções na criança, assim seria necessário que o adulto (inclusive o professor) fizesse uma autoanálise, por meio dos princípios da psicanálise proposta por Ramos para evitar projeções que traumatizariam a criança.

Além disso, segundo Ramos, deve haver a extensão do papel dos pais ao professor. Nessa visão do autor, o docente deve assumir outros papéis ou funções, em vez de apenas transmitir conhecimentos, sobretudo, uma educação moral e da mente. Desse modo, o autor defende a necessidade do conhecimento dos princípios da higiene mental pelo educador, e faz crucial adquirir saberes psicológicos, sociais e culturais, a fim de estabelecer uma relação emocional com o educando, em que relação do docente com este, sobretudo, na educação infantil, se assemelhe a uma extensão do lar no que se refere à autoridade, amor, compreensão e condução da criança.

O livro em questão se apresenta como uma receita pronta e acabada, um manual, de linguagem simples, com orientações direcionadas à família, educadores e população, o qual não considera variáveis que possam influenciar no comportamento e formação humana. Um ponto que destaca a finalidade da obra:

[...] adaptar o indivíduo ao seu meio, tornando-se um auxiliar precioso da administração pública, formando seres harmônicos, sem conflitos de adaptação, ajudando a comunidade, em vez de perturbar o ritmo coletivo e pesar nos orçamentos públicos. Cuidando da infância, a higiene mental quer pôr um termo na onda do crime, da neurose, da loucura, dos conflitos de ajustamento de toda natureza, ou dos inúteis e desocupados que atravancam as avenidas das grandes cidades (RAMOS, 1958:22, grifo nosso).

Quem seria o "desajustado ou anormal” para Ramos? Quem perturbaria o ritmo coletivo e poderia gerar conflitos? Nesse sentido, podemos observar o que Foucault (1992) menciona a "medicina do não patológico" que envolve uma estratégia biopolítica, assim envolve o poder dos médicos sobre o não patológico. Podemos observar também na citação acima um forte interesse e empenho em formar indivíduos produtivos, enquadrando-se na lógica mercantilista do liberalismo. Mesmo envolvendo, um discurso "bonito" em "prol da comunidade", em Ramos (1939), a intenção do higienismo era:

[...] controlar a hereditariedade da grande família dos degenerados e, ao mesmo tempo, controlar as populações e as raças consideradas perigosas: as 
estratégias higiênicas e eugênicas dos séculos XIX e XX. O alvo prioritário dessas estratégias era o controle das famílias dos anormais (CAPONI, 2012:27).

Indo por essa lógica, o desajustado e quem perturbaria o ritmo da sociedade seria o que estivesse desviado da norma, assim: “[...] é preciso definir e redefinir o normal em relação àquilo que lhe é oposto, a figura dos 'anormais' [...] A exceção tem uma função estratégica, que é a de auxiliar na conformação da identidade de um grupo [...]". (CAPONI, 2012:24). Assim, a cultura diferente, dos grupos que representassem ameaças aos interesses da elite deveria ser alvo do campo do higienismo, como já mencionado, a obra foi destinada ao povo. Desse modo, é imprescindível formar, principalmente, os pais e professores para evitar ou corrigir comportamentos considerados inadequados, que por sua vez, podem trazer prejuízos para a sociedade e o Estado, conforme aborda Arthur Ramos, assim, família e professores, são vistos como despreparados, bem como é fortalecida a legitimação da intervenção médica no campo social.

Nesse sentido, educar e civilizar são representados em Ramos como atos "solidários", mas com o mesmo fim de eliminar aspectos adversos e produzir um futuro novo, sem vícios, sem delinquência, sem ociosidade para a sociedade e Estado, garantindo o progresso da nação, conforme Gondra (2005). Observa-se também nessa obra que ela ultrapassa o discurso meramente teórico, pois é o resultado da experiência do alagoano Arthur Ramos, isto significa que foram constatações de sua atuação no Serviço de Higiene Mental, ou seja, este artigo envolve a análise de uma teoria e de uma prática ocorrida no início do século XX.

A proposta de educação higienista proposta por Ramos está baseada no tecnocratismo ${ }^{5}$ sendo esta uma ideologia baseada exclusivamente na ciência para explicar os fenômenos, o qual se afasta da gênese social.

O trabalho nas clínicas seria interdisciplinar: trabalhariam lado a lado o professor, o médico-clínico, o psicopedagogo, o psiquiatra. Como as crianças bem formadas, o trabalho seria 'manter normal a criança normal'; se surgissem casos-problemas, então a higiene mental deveria intervir

\footnotetext{
5 Tecnocratismo é a ideologia que representa o conhecimento científico como a única forma de conhecimento verdadeiro, universal, objetivo, e neutro, apto a reger a existência social dos homens, assegurando sua felicidade através dos instrumentos técnico científicos que legitima, conforme aponta Severino (1986).
} 
procurando resolver e ajustar as dificuldades. Os métodos seriam combinados ou especiais, conforme o caso: observação incidental, fragmentos biográficos, observação sistemática, questionário, história de casos, testes e medidas, experimentação etc. 'É porém, o método do clínico que reúne a maior soma de processos de investigação da personalidade, o mais comumente empregado por nós [...] (RAMOS, 1939: 336, grifo nosso).

Podemos observar que Arthur Ramos considerava a leitura médico-psiquiátrica como principal, pois a dimensão sociológica era subordinada a psicologia ou ao comportamento humano. Portanto, uma de suas limitações seria não ver o humano do ponto de vista filosófico, sociológico e histórico - as condições- reais de vida.

Mesmo com a infância tratada de outra maneira, que por sua vez, havia um investimento no potencial da criança, considerando suas necessidades e interesses, no entanto, a ideia que se tinha da criança era: “[...] a família e a ciência classificam de 'sem razão’, os ‘despossuídos de juízo’ [...]”. (VIDAL, 2008:9). Assim, fazia-se necessário conduzir a criança.

Desta forma, podemos observar uma visão negativa da infância, como o próprio termo derivado do latim infantia que significa sem fala, sem voz, sem pensamento, como afirma Arroyo (2011) uma criança que é vista com uma carga de preconceito sob o olhar do adulto, desvalorizando esse tempo humano, seus saberes, sua identidade. Desse modo, nos contrapomos ao trabalho de Menezes (2002) intitulado A Psicanálise na Bahia (19261937): os estudos de Arthur Ramos sobre a loucura, educação infantil e cultura, o qual a autora destaca:

[...] que o ponto comum entre as correntes da pedagogia, a escola nova, e a psicanálise era o respeito à personalidade da criança. A noção fundamental da nova pedagogia, que a atividade lógica que lhe é própria, é colocada também pela psicanálise. A pedagogia moderna descobriu a criança. (MENEZES, 2002:82, grifo nosso).

Mas como haveria respeito à personalidade da criança, se ela precisaria ser conduzida? Deste modo: “[...] estava na infância o principal campo de ação da higiene mental [...]" (RAMOS, 1958:22). Se houvesse respeito a essa personalidade e a cultura da criança, seria necessário um manual para formar hábitos? Esses hábitos seriam baseados em que comportamentos, cultura, valores, e de qual classe? Por isso, fica difícil 
pensar em respeito às culturas e as personalidades na perspectiva apontada por Arthur Ramos em sua proposta de educação higienista. Assim, a criança de Ramos seria produto de seu meio social e cultural:

O comportamento e o próprio pensamento humano variam no tempo e no espaço. Não há, nunca houve uma maneira rígida e imutável de pensar e julgar. A lógica humana varia nas idades e na geografia, como é relativa a várias condições de 'normalidade' ou 'anormalidade', neurose, psicose, sonho, distração, emoções [...] O homem é produto de sua sociedade e da sua cultura, nesse sentido que estas são responsáveis pelas suas ações [...]. (RAMOS, 1958:32-33, grifo nosso).

Nessa perspectiva, se a criança é produto de sua sociedade e cultura, ela estaria “condenada", no viés da obra Saúde do Espírito (1958) à passividade, à reprodução, desse modo, apenas absorver a formação que seria dada pela sua sociedade, que no caso, seria a sociedade capitalista, mas não de transformá-la, pois não era vista como um ser ativo, que poderia ser diferente do que é transmitido por sua sociedade e cultura, e sim passivo. Ou dito de outra forma, deveria ser, nessa perspectiva liberalista, ativo para o trabalho, para produzir, mas não para transformar a realidade injusta da classe popular, ou melhor, nem poderiam ter acesso ao estar ciente de tal realidade.

$\mathrm{Na}$ visão do psiquiatra alagoano, podemos observar que a criança é entendida como um ser sem autonomia de pensar e agir, que por sua vez, necessita de uma condução do adulto para a formação de sua personalidade, isto é, ser modelada desde a infância para se ajustar à sociedade. Assim, são inculcadas ideias em longo prazo por meio da educação em que os pequenos são passivos, e não ativos. Nesse sentido, se para Arthur Ramos "o homem é produto de sua sociedade e da sua cultura", e estas são responsáveis pelas suas atitudes, à criança não seria um ser livre nem estimulado a desenvolver sua capacidade de pensamento. Assim, nos contrapomos ao trabalho de Garcia (2010):

Longe da visão da criança como ser pacífico e domesticado que deveria receber doses regulares de conhecimentos e reproduzi-los fielmente por meio de memorizações, agora os pequenos eram apresentados como seres em intensa atividade cognitiva que deveriam ser estimulados a se desenvolverem sem os excessos dos cuidados adultos que acabavam sufocando a espontaneidade infantil [...] a defesa da ideia de um novo modelo de educação 
que levasse a criança a pensar, a desenvolver livremente sua capacidade e criatividade [...] (GARCIA, 2010:124-125)

Ao contrário, a referida seria modelada pelo adulto, sobretudo, o educador ilustrado e civilizado, a seu modo e de acordo com seus propósitos. Desse modo, entendemos que a criança necessita de mediações, mas que deve ser proporcionadas experiências que estimulem sua capacidade, expressão de sua cultura, identidades, saberes, realidade, e de um fazer político. Desse modo, convém concordar com Gallo (2009):

A criança, infans, sem palavra, é introduzida no universo da linguagem. Mas não para experimentar sua própria voz, mas para ser enquadrada num sistema semiótico já definido, no qual ela dirá aquilo que se espera que seja dito. Eis o que é aprendido na escola (GALLO, 2009:116).

Além do mais, podemos conjecturar que a criança de Ramos (1958) não é um ser isolado, e, portanto, não deve ser culpabilizada de fracassos escolares ou indisciplina, sem estudar a origem desses problemas, sendo uma contribuição do intelectual para a educação. Assim, buscando através disso dar orientação à família e professores, sendo estes vistos como despreparados, e principais responsáveis pelo comportamento ajustado ou não das crianças e possíveis adultos. Então, aconselha:

Examina a criança em todas as discórdias domésticas, o problema da incompatibilidade matrimonial. Entra no estudo do trabalho humano, dando normas para a orientação vocacional, para a adaptação do homem à sua profissão. Resolve os problemas do sexo. Funda clínicas de hábito e direção da infância e centros de conselhos aos pais. Penetra em todas as atividades humanas da comunidade, prevenindo e resolvendo conflitos, zelando pela saúde psíquica da personalidade humana (RAMOS, 1958:20)

Em linhas gerais, traz a concepção de infância baseada na condução da criança, no entanto, considerando seu desenvolvimento físico baseando em estudos biológicos e psicológicos através de novas teorias sobre o educar e lidar com o aluno, sendo difundida na educação brasileira, não apenas por educadores, mas também por médicos, e neste caso, Arthur Ramos. Vale mencionar que a visão de infância que estava sendo apregoada 
era: "[...] como um estado positivo e não mais como uma fase transitória e inferior" (MENEZES, 2002:77).

Contudo, o estado positivo elencado em Saúde do Espírito (1958), estava embasado no liberalismo representado nos moldes do positivismo, em busca da formação do futuro trabalhador, e não mais inferior, pois a infância tornou-se o elemento central da higiene mental, pois conforme Ramos, para a criança, tudo é novo, tendo mais facilidade para "aceitar", internalizar e aprender, sendo a "idade de ouro" para aplicar os preceitos da higiene mental, até porque a psicanálise aplicada à escola e à família seria uma forma de investigar os processos do inconsciente que poderiam interferir na formação da criança, e assim torná-la uma criança "normal". A higiene mental não foi um movimento intelectual isolado, ela esteve atrelada ao contexto social, político, econômico do liberalismo, positivismo, da racionalidade científica, e principalmente ao avanço do capitalismo industrial no início do século XX.

Uma educação higienista seria de grande relevância na gestão de Anísio Teixeira, escolanovista propagador das ideias de Dewey no Brasil, pois estaria engajada de critério psicológico e científico, de observação, experimentação e controle do comportamento, pois mesmo fora do olhar do fiscalizador, conforme Vidal (2008), o indivíduo agiria de acordo com os interesses da classe dominante, pois foram inculcadas ideias, internalizadas, naturalizadas, ou seja, seriam formados hábitos de conduta, de pensar, agir e sentir, seriam criadas subjetividades autogovernáveis (de si e do outro), conforme a perspectiva de Foucault (1992). Desse modo, o saber médico sobrepuja o saber pedagógico, buscando a formação de uma cultura comum, nacional e de formação de sujeitos que governam a si e ao outro, de forma sútil e naturalizada, normalizada e eficiente.

\section{Considerações Finais}

O propósito deste trabalho não foi dizer qual o melhor modelo de educação, mas que no campo das ideias, a análise de teorias contribui para pensar as limitações e contribuições de intelectuais de uma época que nos possibilitam refletir sobre o presente prejudicado e a pensar sobre nós mesmos e a sociedade, em prol de transformações sociais.

Entendemos que o pensamento de Arthur Ramos expressado na obra Saúde do Espírito (1958) estava imbricado das ideias higienistas por envolver uma proposta de 
formação de hábitos de ser, agir, sentir entrelaçados aos anseios de formação de uma sociedade ideal, elegendo uma cultura como a melhor, ocultando outras, destinando-se a condução da criança da classe popular. Com isso, pudemos perceber o quão grande foi à preocupação em controlar a classe popular tida como "perigosa", e o grande investimento na higienização da mente, demonstrado na articulação do saber médico com a gestão educacional e nacional.

Assim, ao mesmo tempo em que o psiquiatra alagoano colaborou com o processo de escolarização e investia no potencial da infância, havia também uma carga de preconceitos que foram migrados para o campo da mente. A ideia de higienizar a mente é uma atitude profundamente racista, pois sai do campo do determinismo biológico ou genético, indo destes para o racismo cultural, assim impondo um modelo de "cultura" tida como superior, isto é, a "cultura comum" defendida por Teixeira nos moldes do pragmatismo de Dewey.

Entende-se que os problemas sociais como miséria, delinquência, dentre outros no pensamento de Arthur Ramos, são causados pelo comportamento desajustado, como por exemplo a preguiça, psicose, mentira, vícios e etc. A higiene mental seria a "salvação" para prevenir tais comportamentos, e evitar não apenas crianças problemas, mas sobretudo, adultos problemas no futuro. Aspectos econômicos, sociais, políticos, filosóficos ficaram em último plano na concepção do intelectual. Não há uma preocupação com as políticas sociais, pois a higienização da mente, por si só, já seria o suficiente para evitar os problemas sociais, na concepção do médico alagoano. Esse abandono em torno das políticas sociais foi uma realidade desde o período colonial perpassando toda a história brasileira até à atualidade em que o alto investimento econômico através da aliança do Estado com as oligarquias rurais, deixando em total abandono as políticas sociais, visto em índices altos de analfabetismo, criminalidade, violência dos mais diversos aspectos contra a população. Assim, predominava e/ou predomina a busca pelo controle social dessa classe popular representando uma ameaça à elite com sua cultura e suas rebeliões.

Desse modo, tornaria necessário investir numa educação que possibilitasse o acesso ao trabalho, mas que não formasse indivíduos críticos, nesse sentido, o investimento no ensino primário, por isso, a educação apresentada por Ramos (1958) é destinada à classe popular. Com isso, a infância de outrora abandonada, tornou-se o centro dos olhares das classes dirigentes para o controle do futuro adulto, do trabalhador, do cidadão são. 
Vale ressaltar que além dessa proposta de "salvação da nação" pelos higienistas sendo algo de cunho fascista, o pensamento de Arthur Ramos abordada na obra Saúde do Espírito (1958) trouxe algumas contribuições positivas a se pensar sobre educação. Uma delas é a questão da rotulação da criança como "anormal" em que o alagoano apresenta a importância de investigar as causas do comportamento antes de patologizar a criança. Podemos observar que o saber médico esteve entrelaçado à educação, intervindo nela dentro de um contexto social, econômico e político para alcançar finalidades de uma determinada classe social.

Por isso, a importância da análise crítica tendo em vista a historicização como metodologia necessária para dar sentido e revelar o passado, bem como mostrar como se chegou a esse presente prejudicado, sendo isso necessário para construir um novo futuro. Desse modo, compreender o passado como um constituinte para a nossa identidade tanto individual quanto coletiva, bem como revelar os meios de reprodução geradores das mais perversas exclusões sociais, torna-se imprescindível conhecer para modificar, a fim de lutar por uma transformação social.

Contudo, o porquê da necessidade de medicalizar sem refletir sobre a realidade, sobre o contexto sócio-histórico e cultural do indivíduo? Será que há uma tentativa de impedir o acesso e pensamento sobre a realidade? Além disso, quando deixamos de considerar culturas, identidades, saberes, e elegemos ou caímos na armadilha de não fazer política em sala de aula, será que não promovemos o higienismo? Afinal, o higienismo, nada mais seria que impedir um ato profundamente político da classe tida como "perigosa" ao excluir e reduzir os saberes, silenciar identidades, e formar subjetividades pela lógica mercantilista? Podemos observar que ainda hoje são vendidos "manuais", ou a busca por receitas prontas sem considerar o contexto sócio-histórico, condições reais de vida dos educandos, tanto demonstradas em práticas docentes como em discursos. O higienismo traz marcas de uma época que se mostra enraizado ainda hoje em discursos e práticas no meio educacional e social fortemente entrelaçado em relações de poder em que a classe popular sofre as mais perversas injustiças. Cabe a nós, enquanto, educadores políticos, revelar os discursos ideológicos para conhecer o opressor social, descobrindo suas armas e fragilidades, e propor e utilizar estratégias de enfrentamento para uma possível transformação social a começar por cada um de nós, juntos, em prol do bem comum. 


\section{Fontes}

RAMOS, Arthur. (1939). A Criança Problema: a hygiene mental na Escola primária. Rio de Janeiro: Companhia Editora Nacional.

(1958). Saúde do espírito. 7. ed. Rio de Janeiro: edições do SNES.

\section{Referências Bibliográficas}

ARROYO, Miguel G (2011). Currículo, território em disputa. 2 ed. Petrópolis, RJ: Vozes.

BARROS, Luitgarde Calvacanti Oliveira (2005). Arthur Ramos e as dinâmicas sociais de seu tempo. Ed 2. Maceió: EDUFAL.

BLOCH, Marc (2001). Apologia da história ou o ofício do historiador. Rio de Janeiro: Jorge Zahar.

CAPONI, Sandra (2012). Loucos e degenerados: uma genealogia da psiquiatria ampliada. Rio de Janeiro: Fiocruz.

CORAZZA, Sandra (2001). O que quer um currículo? Petrópolis, RJ: Vozes.

DELEUZE, Gille (1992). Post-Scriptum sobre as Sociedades de Controle: conversações Tradução de Peter Pál Pelbar.Rio de Janeiro: Ed. 34, p. 219-226.

DEWEY, John (2011). Experiência e educação. Trad. Renata Gaspar. 2. ed. Petrópolis,

RJ: Vozes.

DOMINGUES, V. R. B (1994). A medicalização da raça: Médicos, educadores e discurso eugênico. Campinas: Ed. da UNICAMP.

FARGE, Arlette (2009). O sabor do arquivo. Trad. Fátima Murad. São Paulo: USP.

FOUCAULT, Michel (1992). Microfísica do poder. Trad. de Roberto Machado. Rio de Janeiro: Edições Graal.

GALLO, Silvio (2009). Infância e poder: algumas interrogações à escola. In: Devir criança da Filosofia. Belo Horizonte, MG: Autêntica, p.109-123.

GARCIA, Ronaldo Aurélio Gimenes (2010). A educação na trajetória intelectual de Arthur Ramos: higiene mental e criança problema (Rio de Janeiro 1934-1949). São Paulo.

GONDRA, José Gonçalves (2005). Artes de civilizar: medicina, higiene e educação escolar na Corte Imperial. Londrina: ANPUH: XXIII Simpósio de História, 2005. Disponível em: <http://anais.anpuh.org/wpcontent/uploads/mp/pdf/ANPUH.S23.0522.pdf> . Acesso em 15 out. 2016.

LAVILLE, Christian; DIONNE, Jean. (1999). A construção do saber: manual de metodologia da pesquisa em ciências humanas. Porto Alegre: ARTMED.

MANSANERA, Adriano Rodrigues; SILVA, Lúcia Cecília da. (2000). A influência das ideias higienistas no desenvolvimento da psicologia no Brasil. Psicol. estud., Mar, vol.5, no.1, pp. 115-137. Disponível em: http://www.scielo.br/pdf/pe/v5n1/v5n1a08.pdf http://www.scielo.br/scielo.php? Acesso em: 23 out. 2014.

MENEZES, Maria Odete (2002). A psicanálise na Bahia (1926-1937): os estudos de Arthur Ramos sobre a loucura, educação infantil e cultura. Dissertação (Mestrado em Ensino, Filosofia e História das Ciências). Universidade Federal da Bahia Universidade Estadual de Feira de Santana. 
RIZZINI, Irma; GONDRA, José Gonçalves (2014). Higiene, tipologia da infância e institucionalização da criança pobre no Brasil (1875-1899). Revista Brasileira de Educação, vol. 19, núm. 58, jul.-sep., pp. 561-584. Associação Nacional de PósGraduação e Pesquisa em Educação. Rio de Janeiro, Brasil. Disponível em: <http://www.scielo.br/pdf/rbedu/v19n58/03.pdf> Acesso em: 10 nov. 2014.

SEVERINO, Antônio Joaquim (1986). Educação, ideologia e contra-ideologia. São Paulo, SP: EPU.

VEIGA, Cynthia. (2007). História da educação. São Paulo: Ática.

VIDAL, Diana Gonçalves (Org.) (2008). Educação e reforma: o Rio de Janeiro nos anos 1920-1930. Belo Horizonte, MG: Argumentom: São Paulo: CNPQ: USP, Núcleo Interdisciplinar de Estudos e Pesquisas em História da Educação.

Artigo recebido em 28 de agosto de 2016.

Aprovado em 12 de abril de 2017.

DOI: 10.12957/intellectus.2017.31659 